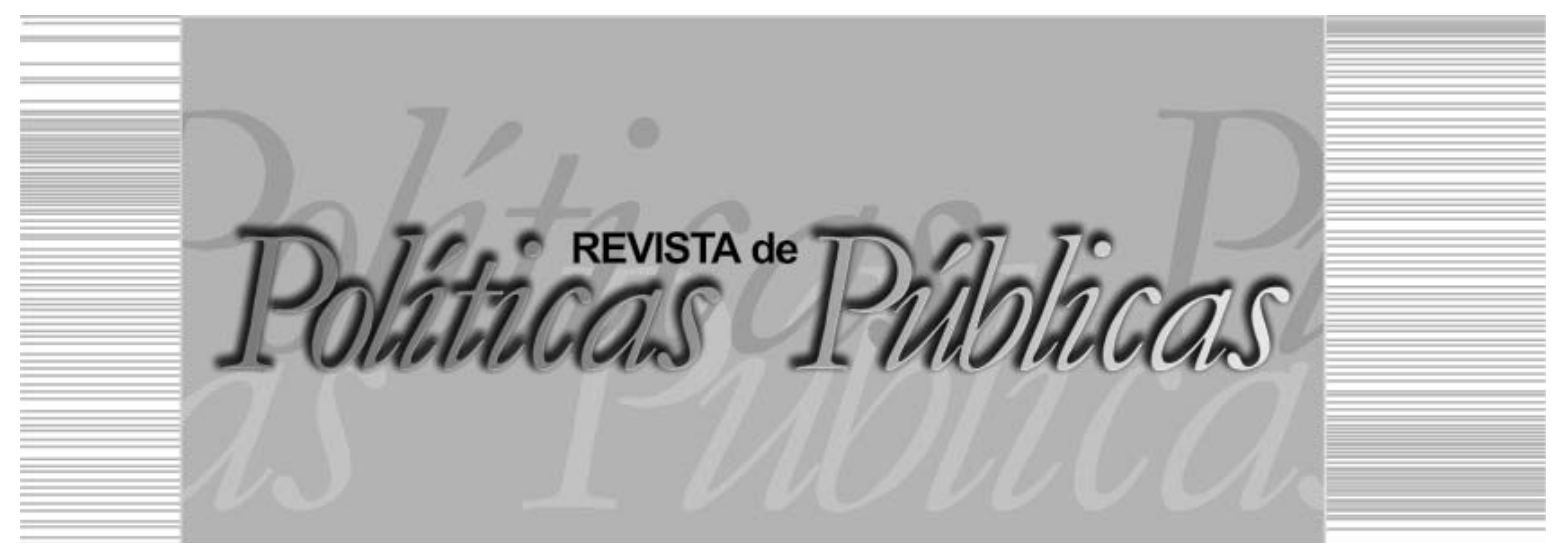

\title{
A PREVIDÊNCIA SOCIAL COMO \\ DETERMINANTE DA DISTRIBUIÇÃO DE RENDA NO ESTADO DO CEARÁ
}

\author{
Rômulo Eufrosino de Alencar Rodrigues ${ }^{l}$ \\ Universidade Regional do Cariri (URCA) \\ Erivelton de Souza Nunes ${ }^{2}$ \\ Universidade Regional do Cariri (URCA) \\ Eliane Pinheiro de Sousa ${ }^{3}$ \\ Universidade Regional do Cariri (URCA)
}

\section{Resumo}

$\mathrm{O}$ artigo faz uma análise da funcionalidade previdenciária cearense quanto à distribuição de renda em nível municipal no ano de 2010. Utiliza estatística descritiva e a estimação de um modelo econométrico de regressão linear múltipla, em que a relação entre arrecadação e despesa previdenciária municipal foi considerada como variável dependente, enquanto as variáveis explicativas foram representadas pelo Produto Interno Bruto (PIB), PIB per capita, número e proporção de idosos na população. Emprega dados do Anuário Estatístico do Ceará, fornecidos pelo Instituto de Pesquisa e Estratégia Econômica do Ceará (IPECE). Os resultados sinalizam que a previdência social cearense, ao possi-

\footnotetext{
Rômulo Eufrosino de Alencar Rodrigues. Economista pela Universidade Regional do Cariri (URCA) | E-mail: romulo-iron@hotmail.com | Universidade Regional do Cariri URCA | Rua Cel. Antônio Luis, 1161 - Pimenta, Crato - CE | CEP: 63100-000

2 Erivelton de Souza Nunes. Economista pela Universidade Regional do Cariri (URCA) | E-mail: erivelton.s.n@hotmail.com

3 Eliane Pinheiro de Sousa. Economista. Doutora em Economia Aplicada e Pós-Doutorado em Economia Aplicada. Professora da Universidade Regional do Cariri (URCA) |E-mail: pinheiroeliane@hotmail.com
} 
bilitar a transferência de renda dos municípios mais ricos para os mais pobres, constitui-se em importante mecanismo redistributivo em nível local.

Palavras-chave: Previdência social, Ceará, regressão linear múltipla.

\title{
SOCIAL SECURITY AS A DETERMINANT OF THE INCOME DISTRIBUTION IN THE STATE OF CEARÁ
}

\begin{abstract}
Given the major relevance of the social security system, this paper aims to analyze the social security functionality of the State of Ceará concerning the income distribution at municipal level in 2010. The methodology adopted consisted of using descriptive statistics and estimating a multiple linear regression econometric model in which the relationship between the municipal social security collection capacity and expenditure was considered as a dependent variable, whereas the explicative variables were represented by the Gross Domestic Product (GDP), per capita GDP, number and rate of elderly people in the population. The data used in this research were extracted from the Statistical Yearbook of the State of Ceará, provided by the Research and Economic Strategy Institute of Ceará (IPECE). The results show that the social security of the State of Ceará is an important mechanism of local income redistribution, insofar as it enables the transfer of income from the richest to the poorest municipalities. Key words: Social security, Ceará, multiple linear regression.
\end{abstract}

\section{INTRODUÇÃO}

O sistema previdenciário brasileiro possui como perfil um sistema de repartição, similar aos empregados na Alemanha, Estados Unidos, Japão e França, no qual os atuais contribuintes financiam os beneficiários (aposentados e pensionistas). É consenso na literatura o não equacionamento desse sistema $\mathrm{e}$, a partir da evidência vivida no Brasil e nesses países, é de comum acordo que este esquema previdenciário tem alcançado progressivos déficits. Como fator adicional ao Brasil, este vem apresentando um agravamento deste déficit devido à transição demográfica que vem ocorrendo (MOURA; TAFNER; JESUS FILHO, 2007).

Para que se possa avaliar, o déficit previdenciário brasileiro tem obtido a ordem de 5\% do Produto Interno Bruto (PIB), um dos mais elevados do mundo (TAFNER; GIAMBIAGI, 2007). Desta maneira, segundo Thompson (2000), os programas de aposentadorias são empreendimentos caros, em que seu custeio requer tipicamente do trabalhador (e/ou empregador) contribuições maiores do 

DO ESTADO DO CEARÁ

que $10 \%$ dos ganhos brutos. Seus fluxos financeiros podem evoluir com facilidade até representarem $5 \%$ a $10 \%$ do PIB do país, ficando distante de qualquer outra atividade do governo.

No desempenho de tamanho impacto na economia brasileira, a Previdência Social tem a finalidade de "Assegurar aos seus beneficiários meios indispensáveis de manutenção, por motivo de incapacidade, idade avançada, tempo de serviço, desemprego involuntário, encargos de família e reclusão ou morte daqueles de quem dependiam economicamente." (BRASIL, 1988, art. 202, 1991, art. 3). Dessa forma, em conformidade com Rezende (1975), para que os programas de previdência desempenhem essa função, é concebível que a Previdência Social promova, em parte, certa distribuição de renda, seja direta ou indiretamente. De modo mais visível, a renda deve ser diretamente redistribuída do sadio para o doente, do capaz para o inválido, do empregado para o desempregado. A redistribuição do indivíduo que possui renda superior para o mais abastado pode ocorrer de forma idêntica, caso o indivíduo de rendimento inferior solicite com maior constância os benefícios do sistema; e as regiões mais pobres recebam recursos de maior volume, por meio do pagamento de benefícios do que aqueles que arrecadam.

De acordo com Oliveira (1987), esta corporação criada pelo Estado tem atribuição de se encarregar das necessidades vitais de todos os que exercem atividade remunerada e de seus dependentes e, em algumas ocasiões, de toda a população, nos eventos previsíveis de suas vidas, por meio de um sistema de seguro obrigatório, do qual a administração e o financiamento competem, em maior ou menor escala, o Estado, os segurados e as empresas.

Conforme Reis e Turra (2011), um dos princípios previdenciários, sob o contexto maior da Seguridade Social, é minimizar o consumo no período de vida correspondente ao período de contribuição, a fim de reduzir a privação de renda nos períodos posteriores, no caso, de incapacidade laboral e pobreza das pessoas desprovidas de recursos para assegurar sua própria aposentadoria, prevenindo, assim, as disparidades sociais insustentáveis.

As contribuições da seguridade social, na medida em que reduzem o orçamento familiar, acabam condicionando a quantia total da renda disponível utilizada para o provimento das necessidades básicas indispensáveis do dia a dia. Partindo dessa prerrogativa, tem-se que o Regime Geral de Previdência Social (RGPS) é pro- 
gressivo do ponto de vista funcional, no sentido de que os retornos da previdência das pessoas de menor rendimento tendem a superar à observada para os indivíduos de maior remuneração (CAETANO, 2006).

Segundo Rangel, Vaz e Ferreira (2009), ao citarem os dados da Pesquisa Nacional por Amostra de Domicílios (PNAD) 2007, destacam que as aposentadorias e pensões pagas pelo governo federal, estados, municípios e Distrito Federal representaram cerca de $18 \%$ da renda total mensurada no ano, sendo que esta participação vem se mantendo estável nos últimos cinco anos. Com base nesses dados, ressaltam também que 79,10 milhões de pessoas vivem em situação de pobreza quando se excluem as rendas oriundas da previdência social (INSTITUTO BRASILEIRO DE GEOGRAFIA E ESTATÍSTICA, 2008). Esse número regride para 56,87 milhões de pessoas em situação de pobreza, quando se consideram os rendimentos de todos os tipos de fontes. Tais informações demonstram a eficiência das transferências previdenciárias, que foram diretamente responsáveis pelo afastamento de aproximadamente 22,23 milhões de pessoas da condição de pobreza. Por se constituir o maior orçamento individual dentre as políticas públicas do Estado brasileiro, e, por abranger uma enorme quantidade de famílias, a previdência social produz impactos em termos de distribuição de renda. Esses efeitos podem ser avaliados pelo lado das receitas e despesas previdenciárias.

Para Reis e Turra (2011), questões regionais referentes à Previdência Social ainda são pouco exploradas na literatura nacional. Dadas as particularidades de cada Grande Região brasileira, assim como o seu próprio processo de evolução socioeconômico ao longo da história, torna-se relevante uma análise minuciosa da ação do Estado, na transferência dos recursos previdenciários, que ultrapasse o contexto geral brasileiro. Dessa forma, é imprescindível investigar se a previdência redireciona recursos, por meio de contribuições, das regiões mais ricas para repassá-los, mediante pagamento de benefícios, para as mais abastadas de recursos financeiros (CAETANO, 2008).

Em face desses argumentos, é de grande importância averiguar a eficiência do fator previdenciário quanto à redistribuição de renda nos diferentes estados brasileiros, a fim de formular melhores estratégias para esse sistema, diante de tamanha heterogeneidade 
entre tais regiões. Nesse contexto, este artigo se propõe analisar a funcionalidade da Previdência Social cearense quanto à distribuição de renda na esfera municipal no ano de 2010. Especificamente, pretende-se avaliar a influência do PIB, PIB per capita, número e proporção de idosos sobre a relação entre arrecadação e despesa previdenciária municipal.

Além dessa seção introdutória, o artigo contempla mais quatro seções, sendo que, na segunda, aborda-se a revisão de literatura, destacando-se a configuração atual da previdência social brasileira, assim como os seus efeitos sobre a distribuição de renda. Na terceira, apresentam-se os procedimentos metodológicos utilizados. Em seguida, os resultados são apresentados e discutidos, e, por fim, a última seção destina-se às principais conclusões do trabalho.

\section{REVISÃO DE LITERATURA}

\subsection{Configuração atual da Previdência Social no Brasil}

A Previdência Social brasileira teve origem em 1923, com a lei Eloy Chaves. Desde então, o sistema de previdência passou por gradativas e significativas mudanças. A princípio, a Previdência Social resume-se nas Caixas de Aposentadorias e Pensões (CAPs) para os ferroviários, portuários e marítimos; portanto, englobava um número limitado de segurados. Sua administração era feita unicamente pelos empregadores e empregados, não restando papel algum ao Estado (FAVONI, 2001; SCHWARZER, 2000; AQUINO; SOUZA, 2007).

Atualmente, o sistema de Previdência Social brasileiro divide-se em quatro grupos, conforme Giambiagi et al (2004 apud LEITE; NESS JUNIOR; KLOTZLE, 2010). O primeiro refere-se ao que presta atendimento ao setor privado, chamado de RGPS. O segundo consiste em um regime de servidores públicos da União, denominado de Regime Jurídico Único (RJU). O terceiro diz respeito aos vários regimes de servidores dos estados e municípios, e, por fim, o quarto é formado pelos patrocínios de empresas privadas ou dos estados a fundos de pensões, que assumem caráter privado e voluntário.

De acordo com Lobo (2003), a Previdência Social brasileira apresenta em sua estrutura dois regimes diferentes, o Regime Pró- 
prio de Previdência Social (RPPS) e o RGPS, ambos de caráter obrigatório e público, que funcionam sob o chamado pacto de gerações, em que trabalhadores economicamente ativos acabam por financiar os benefícios previdenciários dos que já se aposentaram.

Vaz (2009) sinaliza que o sistema previdenciário público da sociedade brasileira apresenta-se como contributivo, em relação aos seus dispêndios, e de repartição, no que se refere ao uso dos recursos por ele obtido, caracterizando-o como um sistema solidário. Distingue-se, assim, do sistema previdenciário privado, caracterizado como um regime de capitalização. $\mathrm{O}$ autor acrescenta ainda que $\mathrm{o}$ sistema previdenciário brasileiro caracteriza-se como misto, isto é, formado por dois sistemas: um com gerência do poder público, de sucessão (filiação) obrigatória para os trabalhadores em geral, apontados pela legislação, e fundamentado em um regime de repartição, com fundo singular; e outro apresentado como complementar, em que o setor privado administra, com sucessão voluntária, fundamentado em um regime de capitalização, em que cada pessoa segurada ajuda em seu próprio fundo, composto por sistemas administrativos realizados por instituições fechadas e sistemas onde entidades abertas administram.

Ao estudar a Previdência Social no Brasil, Camargo (2005) constatou que atualmente os grandes problemas do sistema previdenciário brasileiro são: i) resignações fiscais; ii) alta reserva dos débitos ativos; iii) Estado não cumpre suas obrigações; iv) fraudes fiscais; v) fragilidade das relações trabalhistas; vi) apresentação negativa do sistema; vii) benefícios de assistência; precocidade das aposentadorias, especialmente das mulheres; viii) aposentadorias de elevado grau monetário de parte privilegiada da população; ix) benefícios ofertados aos trabalhadores rurais, que não necessitam de contribuição antecipada, e principalmente, $\mathrm{x}$ ) reduzida cobertura do sistema, dadas as condições atuais do mercado de trabalho brasileiro.

De acordo com Brasil (2009), em 2007 o sistema previdenciário brasileiro envolveu aproximadamente 23 milhões de benefícios sustentados, em que o montante mensal pago girou em torno de $\mathrm{R} \$$ 16,3 bilhões, fazendo do RGPS um dos sistemas previdenciários de maior destaque no âmbito mundial, com cobertura de 53,8 milhões de trabalhadores protegidos. Ademais, acrescenta-se que o RGPS brasileiro segue as regulamentações presentes na Lei $\mathrm{n}^{\circ}$ 8.213, de 
24 de julho de 1991, e engloba trabalhadores urbanos e rurais, tendo como segurados obrigatórios todos os trabalhadores que realizam alguma atividade que implica em remuneração e que não possui, de forma simultânea, ligação a um regime previdenciário próprio.

No tocante ao perfil dos beneficiários do RGPS, Silva e outros (2014) indicam que o número de beneficiários desse regime tem crescido de forma constante, sendo justificada tanto pelas concessões como pelo estoque de aposentadorias, bem como por outros benefícios. Ademais, ressalta-se que tal crescimento pode estar associado ao crescimento demográfico, que tem mostrado elevação do envelhecimento do país, implicando em números cada vez maiores de trabalhadores aposentados, e, com o aumento da esperança de vida populacional, tem-se o aumento da durabilidade média dos benefícios concedidos pela previdência, especialmente, pensões e aposentadorias. As transformações no mercado de trabalho também têm contribuído para o aumento dos benefícios previdenciários. Logo, segundo Lobo (2003), a Previdência Social tem apresentado gastos relativos cada vez maiores, por conta do maior número de beneficiários, e maior duração dos benefícios e da arrecadação bem menor que o seu potencial, consequência dos elevados níveis de desemprego e presença de um mercado de trabalho com alto grau de informalidade, fazendo com que a Previdência Social brasileira realize a cobertura para parte pequena da população.

Nesse sentido, Rangel, Vaz e Ferreira (2009) defendem continuamente que o Sistema Previdenciário do Brasil possui caráter securitário, porém, segundo Magalhães (2009 apud RANGEL; VAZ; FERREIRA, 2009), ainda é possível evoluir no sentido de consolidar os direitos. Entretanto, é fato que o sistema apresenta características notórias de reposição de renda, redistribuindo-a por meio de subsídios cruzados.

\subsection{Efeitos da Previdência Social sobre a distribuição de renda}

O sistema previdenciário brasileiro é uma importante ferramenta da política pública, auxiliando positivamente para a redução da pobreza, das disparidades regionais, assim como para a seguridade do bem-estar social, principalmente nos municípios de pequeno porte mais desabastados de renda (SCHWARZER, 2000; DELGADO, CARDOSO JÚNIOR, 2000). 
Segundo Tafner (2006), a discussão acerca da Previdência Social ramifica-se em duas vertentes. A primeira é que a Previdência Social cumpre seu fundamental papel para o progresso econômico, à medida que reduz a pobreza e assegura a renda. Por outro, embora se reconheçam os efeitos positivos da previdência no combate à pobreza, frisa-se que, no presente momento vivenciado, esses efeitos são inexpressivos e indicam que os custos e as falhas das ações governamentais tendem a comprometer a existência futura do sistema.

Nesse sentido, Ferreira (2006) afirma que distorções no valor de aposentadorias e pensões favorecem uma minoria que recebe uma maior parcela da renda dos benefícios, em detrimento de uma ampla maioria, revelando a ausência dos princípios previdenciários como solidariedade e redistribuição. Isso fica evidente pela falta de uniformidade de critérios e requisitos nos Regimes de Previdência Social brasileira, criando-se regimes especiais, corroborando a redistribuição inversa da renda, onde os que possuem rendimentos menores financiam os que obtêm o beneficio mais cedo e que possuem rendimentos superiores. Os debates acerca dessa questão intensificaram-se a partir da segunda metade da década de 1990, em consequência dos seus significativos e crescentes resultados deficitários.

As causas do sistema previdenciário brasileiro ser regressivo estão em função da aposentadoria mais precoce; maior expectativa de vida; maiores salários no fim do ciclo de vida trabalhista dos beneficiários com maior nível de renda, que são utilizados como base de cálculo do fator previdenciário. Ademais, as causas do crescente déficit do sistema brasileiro estão relacionadas à composição do mercado de trabalho; redução da remuneração por meio do salário fixo, tendo uma complementação do salário sobre participação nos lucros, parcela esta sobre a qual não incidem as alíquotas de contribuição; transição demográfica com aumento da proporção de idosos beneficiários; à nova Constituição aprovada em 1988, que ampliou significativamente o leque de benefícios; e ao aumento da informalidade que corrobora a redução da arrecadação. Estes fatores tornam a distribuição de renda pior e contribuem para a impossibilidade de sustentação do sistema de Previdência Social de longo prazo no Brasil (FERREIRA, 2006).

Em conformidade com Moura, Tafner e Jesus Filho (2007), o sistema previdenciário brasileiro tem se tornado mais progressivo quando se modifica somente os benefícios e contribuições ao nível 
de 1976/1986. Em outros termos, ao longo de duas ou três décadas, as contribuições previdenciárias reduziram mais ainda o nível de desigualdade. No entanto, ao se alterar variáveis relacionadas aos atributos individuais e características geográficas no nível dos anos-bases, o efeito dos benefícios e contribuições ao longo do tempo tem se tornado nulo ou mais regressivo. De acordo com Moura e outros (2013), as mudanças na legislação brasileira da Previdência Social reduziram a desigualdade entre 1987 e 1996, mas apenas para os idosos. Para as demais faixas etárias, há uma tendência estável. Para o período entre 1996 e 2006, os resultados revelam que o sistema brasileiro é neutro para todas as coortes.

Portanto, não há consenso na literatura sobre o papel distributivo da Previdência Social (MOURA; TAFNER; JESUS FILHO, 2007; FREITAS; BARBOSA, 2015).

De acordo com Caetano (2008) e Freitas e Barbosa (2015), os regimes de previdência social se fundamentam em dois objetivos essenciais: a reposição de renda em caso de perda da capacidade laborativa e a redução da pobreza por meio da distribuição de recursos de grupos mais ricos para grupos mais pobres. Em relação a este último aspecto, a distribuição de renda pode ser analisada por três perspectivas distintas: regional, setorial e funcional.

Dentro da perspectiva regional, mais especificamente municipal, os estudos desenvolvidos por Caetano (2008), Sausen, Freitas e Pauli (2010) e Freitas e Barbosa (2015) buscaram analisar como a Previdência Social brasileira influencia a distribuição de renda sob a ótica municipal. Para atender a esse objetivo nos municípios brasileiros e municípios gaúchos, respectivamente, os dois primeiros estudos empregaram modelos econométricos de regressão linear múltipla, pelo método dos Mínimos Quadrados Ordinários. Além dessa ferramenta analítica, o último estudo utiliza a curva de Lorentz, índices de Gini e Theil para mensurar o grau de dispersão das rendas. Os resultados obtidos nesses estudos revelam que a Previdência Social desempenha um papel redistribuidor de renda. O presente artigo segue a linha desses estudos, sendo aplicado aos municípios cearenses. 


\section{METOdologia}

\section{1 Área de estudo e natureza dos dados}

Este estudo foi realizado em todos os municípios cearenses e os dados empregados são de origem secundária, provenientes do Anuário Estatístico do Ceará, fornecido pelo Instituto de Pesquisa e Estratégia Econômica do Ceará (IPECE) (2012).

\subsection{Método analítico e variáveis consideradas}

Para atender ao objetivo proposto, empregou-se um modelo econométrico de regressão linear múltipla, estimado por meio do método dos Mínimos Quadrados Ordinários (MQO), com forma funcional $\log -\log$. Esse modelo, com tal especificação funcional, vem sendo muito utilizado, pois, conforme Gujarati (2006), fornece diretamente as elasticidades parciais da variável dependente em relação à explicativa, podendo ser mensurada pelo próprio coeficiente estimado dessa variável explicativa.

Nesse sentido, conforme Caetano (2008), Sausen, Freitas e Pauli (2010) e Freitas e Barbosa (2015) algebricamente, o modelo empregado neste artigo pode ser representado pela equação (1), descrita a seguir:

$$
\ln \text { ARDESP }_{i}=\alpha_{i}+\beta_{1} \ln I D O S O S+\beta_{2} \ln P I B T+\beta_{3} D U M M Y+\mu_{i}(1)
$$

Em que: ARDESP se refere à relação entre arrecadação e despesa previdenciária total; IDOSOS, população idosa com idade igual ou superior a 65 anos, por município; PIBT, Produto Interno Bruto do município considerado, mensurado em R $\$$ mil; DUMMY $=0$, caso o município apresente arrecadação previdenciária, e um, caso contrário; Ln, Logaritmo natural; i =indica o município considerado; $\alpha_{i}=\ln \beta_{0} ; \beta_{1}, \beta_{2}, \beta_{3}$, parâmetros a serem estimados; e $\mu$, Erro estocástico.

A equação (1) busca analisar se a Previdência Social vem a ser uma ferramenta de redistribuição de renda por meio da utilização de variáveis absolutas, isto é, população idosa municipal e PIB total dos municípios.

De acordo com Caetano (2008), o município será superavitário se a relação entre arrecadação e despesa previdenciária for 
positiva, e deficitário se for negativa. Caso seja nula, significa que o município não arrecada para o RGPS. Seguindo a recomendação desse autor, considerou-se um valor arbitrário baixo, de 0,00003 para o quociente, com o intuito de permitir o cálculo, já que não há logaritmo de zero.

Como alternativa para mensuração dessa relação, empregou-se a equação (2), que relativiza as variáveis, utilizando a proporção de idosos na população municipal e o Produto Interno Bruto per capita, ou seja, aproxima-se mais os coeficientes analisados da realidade municipal. Essa equação pode ser expressa por:

$$
\ln \text { ARDESP }_{i}=\alpha_{i}+\gamma_{1} \ln \% I D O S O S+\gamma_{2} \ln P I B P+\gamma_{3} D U M M Y+\varepsilon_{i} \text { (2) }
$$

Em que: ARDESP, conforme descrito, diz respeito à relação entre arrecadação e despesa previdenciária total; \% IDOSOS, representa a proporção de idosos com idade igual ou superior a 65 anos, por município; PIBP, Produto Interno Bruto per capita, mensurado em R \$; DUMMY $=0$, caso o município apresente arrecadação previdenciária, e um. caso contrário; i indica o município considerado; $\alpha_{i}=\ln \gamma_{0} ; y_{1} y_{2} y_{3} \gamma_{1}, \gamma_{2}, \gamma_{3}$, parâmetros a serem estimados; e $\varepsilon$ , erro estocástico.

A utilização desses modelos é adequada ao escopo da pesquisa, na medida em que permite a captação da correlação entre o PIB per capita dos municípios cearenses, número de idosos e municípios que não possuem arrecadação, sobre a proporção existente entre a arrecadação e a despesa previdenciária, conforme apontam Freitas e Barbosa (2015). Ademais, os autores ressaltam que se torna possível analisar o comportamento da transferência de renda dos ricos para os pobres e apresentar a tendência de transferência de renda dos municípios mais ricos para os de menores poderes aquisitivos.

Espera-se que $\beta_{1}$ e $\gamma_{1}$ tenham valores estatísticos inferiores a zero, sinalizando que quanto mais idosos no município, maior será sua tendência em apresentar resultados previdenciários abaixo de zero. Por outro lado, $\beta_{2}$ e $\gamma_{2}$ sejam positivos, ou seja, pressupõem maneiras alternativas de se observar uma previdência progressiva, regionalmente, haja vista que os municípios mais providos de renda tendem a exibir fluxos financeiros maiores que os municípios de menor renda, significando que os municípios mais ricos redistribuem suas rendas por meio do mecanismo previdenciário para os municípios mais pobres. Contrariamente, os valores inversos, para 
os respectivos parâmetros já citados, implicam uma previdência com características de regressão na região. Finalmente, tem-se que, caso a Dummy apresente valor negativo, pode-se supor que quanto mais municípios sem arrecadação previdenciária, menores serão as razões entre arrecadação e despesa, que se trata da variável dependente considerada na análise. Tais hipóteses foram apontadas por Caetano (2008), Sausen, Freitas e Pauli (2010) e Freitas e Barbosa (2015).

Ademais, salienta-se que foram utilizados os testes de heterocedasticidade de White, de multicolinearidade, por meio da Variable Inflaction Factor (VIF) e de normalidade Jarque-Bera (JB), a fim de corrigir possíveis problemas de violação dos pressupostos no modelo analítico.

A escolha das variáveis consideradas neste trabalho foi baseada nos estudos propostos por Caetano (2008), Sausen, Freitas e Pauli (2010) e Freitas e Barbosa (2015) e são definidas da seguinte forma:

a) Arrecadação previdenciária total: Os dados referentes à arrecadação previdenciária dizem respeito aos valores recolhidos de todas as receitas que fazem parte da Guia da Previdência Social (GPS), entre os meses de janeiro e dezembro de cada ano considerado. Englobam receitas de contribuições da sociedade, tais como, empresas, entidades equiparadas e contribuições, em geral; débitos e parcelamentos patrimoniais, devolução de benefícios, reclamatória trabalhista e outros.

b) Despesa previdenciária total: Os dados relativos à despesa previdenciária total referem-se aos valores líquidos dos créditos emitidos pelos municípios, visando o pagamento de benefícios, e assim, como no caso da arrecadação previdenciária, é considerado o período de janeiro a dezembro de cada ano.

c) Número absoluto e proporção de idosos na população total: Para saber a proporção de idosos dos municípios cearenses, foi necessário calcular a percentagem de idosos por município de acordo com a população.

d) PIB: Esta pesquisa considera tanto o PIB total dos municípios, como o PIB per capita municipal. Segundo Tremea (2011), o Produto Interno Bruto consiste na somatória de toda a produção, ao longo de certo espaço temporal, de 
bens e serviços finais, normalmente por ano. Seu cálculo pode ocorrer sobre visões diferentes, sendo considerados valores acrescidos por determinados setores da economia, de maneira que o resultado final deve ser igual à renda proporcionada, assim como pela despesa da população.

Nesse estudo, os dados relacionados ao PIB total contemplam o PIB a preços de mercado, sendo considerado o valor adicionado a preços básicos fornecidos pelas várias áreas da economia que constituem os setores da Agropecuária, Indústria e Serviços. Os dados relacionados ao PIB per capita foram obtidos por meio da divisão do PIB Total do município pela população municipal.

\section{RESULTADOS E DISCUSSÃO}

\subsection{Perfil socioeconômico dos municípios cearenses}

Nesta seção serão apresentadas e discutidas as informações socioeconômicas dos municípios cearenses, referentes ao PIB total e per capita municipal, arrecadação e despesa previdenciária, quantidade de benefícios concedidos, número total e proporcional de idosos em 2010.

Como pode ser observado na Tabela 1, o PIB médio dos municípios estudados, no ano de 2010, perfez cerca de 423 mil reais, valor menor ao da média dos municípios brasileiros, em 2010, que corresponde a R \$ 677 mil reais, conforme dados do Instituto Brasileiro de Geografia e Estatística (IBGE) (2013). Considerando o PIB per capita, verifica-se que os municípios cearenses apresentam uma média de $\mathrm{R} \$ 5.445,35$, menor que a média nacional apontada pelo IBGE (2013), que é de R \$ 19.763,93. Esses dados demonstram que, em termos médios, tanto o PIB total quanto o PIB per capita nos municípios cearenses estão bem abaixo da média obtida pelos municípios brasileiros.

A capital cearense se destaca com o maior PIB total, porém o município de Quixeré foi o que registrou o maior PIB per capita. Em contrapartida, os municípios de Granjeiro e Catarina foram, respectivamente, os que tiveram os menores PIB total e per capita. 
Tabela 1 - Estatísticas descritivas das variáveis socioeconômicas dos municípios cearenses, 2010

\begin{tabular}{cccccccc}
\hline Estatistica & PIB & $\begin{array}{c}\text { PIB } \\
\text { per capita }\end{array}$ & $\begin{array}{c}\text { Arrecadaçãa } \\
\text { Previdenciária }\end{array}$ & $\begin{array}{c}\text { Despesa } \\
\text { Previdenciárial }\end{array}$ & $\begin{array}{c}\text { Quantidade } \\
\text { benefícios } \\
\text { concedidos }\end{array}$ & $\begin{array}{c}\text { Número } \\
\text { absoluto } \\
\text { de idosos }\end{array}$ & $\begin{array}{c}\text { Número } \\
\text { proporcional } \\
\text { de idosos } \\
(\%)\end{array}$ \\
\hline Mínimo & $19.559,58$ & $3.168,52$ & 0,00 & $1.637,94$ & 286,00 & 337,00 & 4,69 \\
Média & $423.181,60$ & $5.445,35$ & $20.165,60$ & $45.437,75$ & $6.709,90$ & $3.486,72$ & 8,72 \\
Máximo & $37.106 .309,48$ & $39.997,39$ & $2.743 .003,00$ & $2.397 .691,45$ & $268.396,00$ & $161.387,00$ & 12,43 \\
Desvio Padrão & $2.747 .798,14$ & $4.013,48$ & $201.546,39$ & $177.361,67$ & $20.080,71$ & $11.933,97$ & 1,51 \\
CV (\%) & 649,32 & 73,70 & 999,46 & 390,34 & 299,27 & 342,27 & 17,30 \\
\hline
\end{tabular}

Fonte: Elaborado pelos autores, com base nos resultados da pesquisa. Nota: Arrecadação e despesa previdenciária em mil reais.

* $\mathrm{CV}(\%)$ corresponde ao coeficiente de variação.

Dentre essas variáveis, a arrecadação previdenciária por município foi a que apresentou a maior heterogeneidade, em que varia de $R \$ 0,00$ a $R \$ 2.743 .003,00$, sendo que, em termos médios, equivale a aproximadamente $\mathrm{R} \$ 20.165,60$. Conforme Caetano (2008), uma das características pertinentes ao sistema previdenciário brasileiro refere-se ao fato de que parcela expressiva dos municípios brasileiros não apresenta arrecadação previdenciária. No Ceará, 40 municípios não registraram arrecadação, enquanto apenas Eusébio e a capital cearense, que fazem parte da Região Metropolitana de Fortaleza, obtiveram superávits previdenciários.

No tocante à despesa previdenciária, em termos médios, foi de cerca de $\mathrm{R} \$ 45.437,00$, valor bem superior à média da arrecadação previdenciária. Guaramiranga registrou a menor despesa previdenciária e o menor número de benefícios concedidos, enquanto Fortaleza liderou a maior despesa previdenciária e a maior quantidade de benefícios concedidos no Ceará. Considerando dados divulgados pelo Banco Mundial, Cysne (2010) mostra que os gastos brasileiros com a previdência são bastante altos, perfazendo $11,7 \%$ do PIB, sendo que somente $6,6 \%$ da população apresenta idade superior aos 65 anos, evidenciando grande assimetria do Brasil em relação a outros países.

No que tange ao número absoluto e proporcional de idosos presentes nos municípios considerados, estes apresentaram médias de aproximadamente 3.487 e $9 \%$, respectivamente. Vale destacar que o maior contingente de pessoas idosas se encontra em Fortaleza, enquanto o município de Guaramiranga registrou o menor contingente. Entretanto, em termos proporcionais, o município de São João do Jaguaribe é que lidera esse ranking, ao passo que Pacatuba teve a menor participação relativa cearense de idosos. Ademais, ressalta-se que o número proporcional de idosos no Ceará foi a variável 
considerada que apresentou maior homogeneidade, uma vez que se obteve o menor coeficiente de variação, dentre as demais.

\subsection{Análise econométrica dos dados}

Os resultados da análise de regressão indicaram que não foi encontrada a presença de heterocedasticidade, haja vista que a estatística $\mathrm{F}$ do teste de heterocedasticidade de White não foi significante a $1 \%$, sendo aceita a hipótese nula de homocedasticidade. Como o valor do VIF foi inferior a 10 para todas as variáveis, constata-se que o modelo não apresentou problema de multicolinearidade.

As estimativas para a arrecadação/despesa previdenciária, em termos absolutos, descritas na Tabela 2 , indicam que o modelo empregado é adequado, uma vez que a estatística $\mathrm{F}$ é significativa a $1 \%$ de probabilidade.

Tabela 2 - Estimativas obtidas por meio da primeira regressão

\begin{tabular}{ccccc}
\hline $\begin{array}{c}\text { Variáveis } \\
\text { explicativas }\end{array}$ & $\begin{array}{c}\text { Coeficiente } \\
\text { Estimado }\end{array}$ & Valor de t & $\begin{array}{c}\text { Desvio } \\
\text { Padrão }\end{array}$ & $\begin{array}{c}\text { Nivel de } \\
\text { Significância }\end{array}$ \\
\hline Constante & $-5,1921$ & $-9,50$ & 0,55 & 0,000 \\
LNIDOSOS & $-0,4442$ & $-3,43$ & 0,13 & 0,001 \\
LNPIBT & 0,5525 & 6,03 & 0,09 & 0,000 \\
DUMMY & $-8,0654$ & $-65,79$ & 0,12 & 0,000 \\
\hline $\mathrm{R}^{2}$ ajustado $=0,9724 ;$ & $\mathrm{DW}=1,94 ;$ Valor de $\mathrm{F}=2.151,42 ;$ Prob. (Estatística $\mathrm{F}$ ): 0,000 \\
\hline
\end{tabular}

Fonte: Elaborado pelos autores, com base nos resultados da pesquisa.

Nota: DW refere-se à estatística de Durbin-Watson.

Os coeficientes das variáveis referentes ao número absoluto de idosos, PIB Total e a Dummy foram estatisticamente significativos e podem ser interpretados como elasticidades, já que essas variáveis estão expressas em logaritmos. Tais variáveis incorporadas à regressão são capazes de explicar 97,24\% das variações ocorridas na relação arrecadação/despesa previdenciária.

Portanto, observa-se que, Coeteris paribus, um acréscimo de $10 \%$ no número de idosos proporcionará redução de $4,44 \%$ na relação arrecadação/despesa previdenciária. Esse resultado está de acordo com o demonstrado por estudos correlatos e satisfaz a relação esperada nesta pesquisa, haja vista que, em termos absolutos, a quantidade de idosos é capaz de influenciar a necessidade de elevação dos financiamentos da previdência, que é o que se espera de uma política social, em que uma das finalidades trata-se da reposição de renda em face da redução da capacidade produtiva de pessoas com idades mais avançadas, conforme aponta Caetano (2008). 
Mantendo as demais variáveis constantes, infere-se que uma variação positiva de $10 \%$ no PIB total dos municípios cearenses, pode gerar crescimento de 5,53\% na relação arrecadação/despesa previdenciária entre tais municípios. Tal resultado também está em conformidade com a literatura, na medida em que a previdência mostra-se como uma forma de redistribuição de renda, em termos regionais, fato comprovado pela influência positiva do PIB total sobre o volume de arrecadação previdenciária quanto aos pagamentos dos benefícios concedidos.

Já a variável binária, que indica se o município possui ou não arrecadação previdenciária, mostra que há uma relação contrária com a variável dependente, sinalizando que municípios maiores sem arrecadação implicaram em menores razões arrecadação/despesa previdenciária. Dessa forma, se houver o aumento de $1 \%$ na variável dummy, ocorrerá variação negativa de $8,06 \%$ na arrecadação/despesa previdenciária.

Nesse sentido, pode-se notar que, em termos absolutos, a previdência social tem ação instrumental de relevância para os municípios cearenses, sendo que aqueles que possuem maiores rendas agem no sentido de amenizar problemas previdenciários nos municípios mais pobres.

No que concerne à segunda regressão, que busca verificar a relação da arrecadação/despesa previdenciária em termos relativos, não se verificou a presença de heterocedasticidade, já que a estatística $\mathrm{F}$ do teste de heterocedasticidade de White não foi significante a $1 \%$. Desta forma, aceita-se a hipótese nula de homocedasticidade, ou seja, as perturbações $\mu$ i têm a mesma variância. Realizou-se o teste de correlação serial, e o modelo não apresentou problema de autocorrelação, assim como o valor do teste de Durbin-Watson já apontava. Verificou-se ainda que o valor VIF foi inferior a 10 para todas as variáveis, não apresentando, portanto, problema de multicolinearidade.

Como se verifica pela Tabela 3 , o teste $\mathrm{F}$ foi significante a $1 \%$, logo o modelo é válido, sendo possível sua interpretação em termos de elasticidade, pois os regressores estão expressos em logaritmos. Considerando-se o efeito individual de cada variável explicativa sob a dependente, tudo o mais constante, os coeficientes possuem significância a $1 \%$, assim como os sinais esperados. 
A PREVIDÊNCIA SOCIAL COMO DETERMINANTE DA DISTRIBUIÇÃO DA RENDA DO ESTADO DO CEARÁ

Tabela 3 - Estimativas obtidas por meio da segunda regressão

\begin{tabular}{ccccc}
\hline $\begin{array}{c}\text { Variáveis } \\
\text { explicativas }\end{array}$ & $\begin{array}{c}\text { Coeficiente } \\
\text { Estimado }\end{array}$ & Valor de t & $\begin{array}{c}\text { Desvio } \\
\text { Padrão }\end{array}$ & $\begin{array}{c}\text { Nível de } \\
\text { Significância }\end{array}$ \\
\hline Constante & $-3,12$ & $-1,96$ & 1,59 & 0,052 \\
LNPERCIDOSOS & $-1,11$ & $-3,96$ & 0,28 & 0,000 \\
LNPIBPC & 0,40 & 2,88 & 0,14 & 0,005 \\
DUMMY & $-8,18$ & $-75,59$ & 0,11 & 0,000 \\
\hline $\mathrm{R}^{2}$ ajustado $=0,9725 ; \mathrm{DW}=1,97 ;$ Valor de $\mathrm{F}=2.156,84$; Prob. (Estatística $\mathrm{F}$ ) 0,000 \\
\hline
\end{tabular}

Fonte: Elaborado pelos autores, com base nos resultados da pesquisa.

Nota: DW refere-se à estatística de Durbin-Watson.

A variável proporção de idosos possui uma relação inversa com a variável arrecadação/ despesa previdenciária, indicando que quanto mais elevado o número de idosos na população municipal maior será a tendência aos saldos negativos da previdência no mesmo, sendo que um aumento de $10 \%$ na proporção de idosos, gera uma variação negativa de $11,1 \%$ na variável dependente.

A segunda variável a ser analisada, PIB per capita, possui uma relação direta com a variável dependente. Assim, municípios que possuem maior PIB per capita têm maior probabilidade de terem um saldo positivo previdenciário. Em termos numéricos, um aumento de $10 \%$ nessa variável explicativa, representa uma variação positiva de $4 \%$ na arrecadação/despesa previdenciária.

A Dummy, caso não apresente arrecadação previdenciária, por sua vez, demostra uma relação inversa com a variável dependente, indicando que quanto maior for o município que não possui arrecadação previdenciária, menor será a razão arrecadação/ despesa previdenciária. Assim, um aumento de $1 \%$ na Dummy acarretará uma variação negativa de $8,18 \%$ na variável dependente.

Pode-se inferir ainda que 97,29\% das variações ocorridas na relação entre arrecadação/despesa previdenciária são explicadas pela proporção de idosos, PIB per capita e pela variável Dummy.

Assim, com base nas estimativas obtidas neste artigo, constata-se que a previdência atua como importante ferramenta de redistribuição de renda nos municípios cearenses. Esta situação também foi verificada em estudos de mesma natureza realizados por Caetano (2008), Sausen, Freitas e Pauli (2010) e Freitas e Barbosa (2015). 


\section{CONCLUSÃO}

Dentre os 184 municípios cearenses, apenas Eusébio e Fortaleza apresentaram superávits previdenciários, enquanto 40 municípios não obtiveram nenhuma arrecadação. Em média, observou-se que os dispêndios previdenciários no estado excederam muito a arrecadação média previdenciária no Estado do Ceará. Os gastos com a Previdência Social permitem maior igualdade entre os municípios, possibilitando, dessa forma, o desempenho relevante dessa ferramenta, no que concerne à redistribuição de renda.

No tocante aos resultados econométricos, constata-se que o aumento no número de idosos gera diminuição na relação arrecadação/despesa previdenciária, tanto em termos absolutos quanto em termos relativos. Por outro lado, Coeteris Paribus, o aumento no PIB Total e no PIB per capita dos municípios cearenses, acarreta aumento na variável dependente. A variável binária também apresentou variações na mesma direção, ou seja, o fato de o município arrecadar ou não, influencia a relação entre arrecadação e despesa previdenciária. Assim, os municípios que mais arrecadam são mais importantes como ferramentas de redistribuição de renda.

Portanto, pode-se concluir que ocorre um perfil redistribuidor de renda por parte da Previdência Social cearense, permitindo a transferência de renda dos municípios ricos para os mais pobres.

\section{REFERÊNCIAS}

AQUINO, J. R.; SOUZA, R. C. Impactos socioeconômicos da previdência rural no Brasil: um estudo de caso no município de Encanto/RN. In: CONGRESSO DA SOCIEDADE BRASILEIRA DE ECONOMIA, ADMINISTRAÇÃO E SOCIEDADE RURAL, 45., 2007, Londrina, PR. Anais... Londrina, PR: SOBER, 2007.

BRASIL. Ministério da Previdência Social. Previdência Social: Reflexões e Desafios. Brasília: MPS, 2009. 232 p. (Coleção Previdência Social, Série Estudos; v. 30, 1. Ed.).

Presidência da República. Lei no ${ }^{\circ}$.212, de 24 de julho de 1991. Dispõe sobre a finalidade da Previdência Social. Diário Oficial da União, Brasília, DF, 1991. Disponível em: <http://www.previdencia. gov.br/legislao/> Acesso em: 29 de março de 2015.

Senado Federal. Artigo 201 da Constituição da República Federativa do Brasil. Brasília, DF, 1988. Disponível em:<http://www. 
A PREVIDÊNCIA SOCIAL COMO DETERMINANTE DA DISTRIBUIÇÃO DA RENDA DO ESTADO DO CEARÁ

senado.gov.br/legislacao/const/con1988/CON1988_13.07.2010/ art_201_.shtm> Acesso em: 29 mar. 2015.

CAETANO, M. A. Previdência Social e distribuição regional da renda. Texto para discussão, Brasília, DF, n. 1318, 2008.

. Subsídios cruzados na previdência social brasileira. Texto para discussão, Brasília, DF, n. 1211, 2006.

CAMARGO, P. T. Previdência Social no Brasil. 2005. 42 f.

Monografia (Graduação em Ciências Econômicas) - Universidade Estadual de Campinas, Campinas, SP, 2005.

CYSNE, R. P. Previdência: Brasil na contramão mundial. Conjuntura Econômica, [S. 1.], v. 64, n. 7, p. 70-72, 2010.

DELGADO, G.; CARDOSO JÚNIOR, J. C. Principais resultados da pesquisa domiciliar sobre a previdência rural na região sul do Brasil (Projeto avaliação socioeconômica da previdência social rural). Texto para discussão, Rio de Janeiro, n. 734, 2000.

FAVONI, C. A previdência social brasileira como política pública de renda nos municípios. Revista Conjuntura Social, Rio de Janeiro, v. 12, p. 69-122, 2001.

FERREIRA, C. R. Aposentadorias e distribuição da renda no Brasil: uma nota sobre o período 1981 a 2001. Revista Brasileira de Economia, Rio de Janeiro, v. 60, n. 3, p. 247-260, 2006.

FREITAS, C. E.; BARBOSA, R. R. A previdência social e as distorções na distribuição de renda. Pesquisa \& Debate, São Paulo, v. 26, n. 1(47), p. 173-197, 2015.

GUJARATI, D. Econometria Básica. Rio de Janeiro: Elsevier, 2006.

INSTITUTO BRASILEIRO DE GEOGRAFIA E ESTATÍSTICA. Pesquisa Nacional por Amostra de Domicílios 2007. Rio de Janeiro, 2008

. Produto Interno Bruto dos Municípios 2011. Rio de Janeiro, 2013. (Contas Nacionais, n. 41). Disponível em: <http://www.ibge. gov.br/home/estatistica/economia/contasnacionais/2011/defaulttab_ xls.shtm>. Acesso em 27 maio 2015.

INSTITUTO DE PESQUISA E ESTRATÉGIA ECONÔMICA DO CEARÁ. Anuário Estatístico do Ceará. Fortaleza, 2012. Disponível em: <http://www2.ipece.ce.gov.br/publicacoes/anuario/anuario2012/ index.htm> Acesso em: 25 set. 2013. 
LEITE, A. R.; NESS JUNIOR, W. L.; KLOTZLE, M. C. Previdência Social: fatores que explicam os resultados financeiros. Revista de Administração Pública, Rio de Janeiro, v. 44, n. 2, p. 437-457, 2010.

LOBO, B. A atual situação do sistema previdenciário brasileiro e as propostas de reforma do Governo Lula. Conjuntura \& Planejamento, Salvador, n.111, p. 20-25, 2003.

MOURA, R. L. et al. Social security effects on income distribution: a counterfactual analysis for Brazil. Applied Economics Letters, Coventry, v. 20, p. 631-637, 2013.

. TAFNER, P.; JESUS FILHO, J. Impactos da previdência na distribuição de renda: uma análise contrafactual para o Brasil. In: ENCONTRO NACIONAL DE ECONOMIA, 35., 2007, Recife. Anais... Recife, PE: ANPEC, 2007.

OLIVEIRA, M. V. C. Previdência Social. Rio de Janeiro: Freitas Bastos, 1987.

RANGEL, L.; VAZ, F.; FERREIRA, J. Desigualdade na distribuição de renda: enfoque nas aposentadorias e pensões públicas. Informe de Previdência Social, Brasília, DF, v. 21, n. 5, p. 1-24, 2009.

REIS, C. B.; TURRA, C. M. Desigualdade regional na distribuição dos recursos previdenciários: uma análise das transferências intrageracionais e de período. Texto para discussão, Belo Horizonte, n. 447, p. 3-29, 2011.

REZENDE, F. Redistribuição de renda através da previdência social: o caso brasileiro. Revista de Administração Pública, Rio de Janeiro, v. 10, n. 4, p. 7-19, 1975.

SAUSEN, D.; FREITAS, C.; PAULI, R. I. P. A Previdência Social como determinante da distribuição da renda regional: uma análise econométrica. In: CONGRESSO DA SOCIEDADE BRASILEIRA DE ECONOMIA, ADMINISTRAÇÃO E SOCIOLOGIA RURAL, 48., 2010, Campo Grande. Anais... Campo Grande, MT: SOBER, 2010.

SCHWARZER, H. Impactos socioeconômicos do sistema de aposentadorias rurais no Brasil: evidências empíricas de um estudo de caso no estado do Pará. Texto para discussão, Rio de Janeiro n. 729, 2000.

SILVA, E. P. et al. O perfil dos beneficiários do Regime Geral de Previdência Social (RGPS). Informe de Previdência Social, Brasília, DF, v. 16, n. 2, p. 4- 35, fev. 014. 
A PREVIDÊNCIA SOCIAL COMO DETERMINANTE DA DISTRIBUIÇÃO DA RENDA DO ESTADO DO CEARÁ

TAFNER, P. Brasil: O Estado de uma Nação. IPEA, Rio de Janeiro, 2006.

GIAMBIAGI, F. Introdução. In: TAFNER, P.; GIAMBIAGI, F. (Eds.) Previdência no Brasil: debates, dilemas e escolhas. Rio de Janeiro: IPEA, 2007. p. 11-25

THOMPSON, L. Mais velha e mais sábia: a economia dos sistemas previdenciários. Brasília, DF: Ministério da Previdência e Assistência Social, 2000.

TREMEA, N. J. C. As exportações e o Produto Interno Bruto do Brasil no período de 2000 a 2009. Revista ADMpg Gestão Estratégica, Ponta Grossa, v. 4, n. 1, p. 1-9, 2011. Disponível: <http://www.admpg. com.br/revista2011/artigos/6.pdf $>$ Acesso em: 19 de maio de 2015.

VAZ, L. R. O princípio do equilíbrio financeiro e atuarial no sistema previdenciário brasileiro. Revista Direitos Fundamentais e Democracia, Curitiba, v. 6, p. 4-35, 2009. 
